\title{
Effects of Dietary Unsaturated Fatty Acids on Oocyte Quality and Follicular Development in Lactating Dairy Cows in Summer
}

\author{
T. R. Bilby, J. Block, B. C. do Amaral, O. Sa Filho, F. T. Silvestre, \\ P. J. Hansen, C. R. Staples, and W. W. Thatcher ${ }^{1}$ \\ Department of Animal Sciences, University of Florida, Gainesville 32611-0910
}

\section{ABSTRACT}

Dietary sources of fatty acids were evaluated for their influence on oocyte quality and follicular development using 54 lactating cows in summer. Fat supplements were 1) sunflower oil ( $80 \%$ cis 18:1), 2) Ca salt of transoctadecenoic acids (57\% trans 18:1),3) Ca salt of vegetable oils (30\% 18:2), and 4) linseed oil (56\% 18:3 and $16 \% 18: 2)$. Fats were fed at $1.35 \%$ of dietary dry matter beginning at $5 \mathrm{wk}$ prior to expected calving date and at $1.5 \%$ (oils) and $1.75 \%$ (Ca salts) of dietary dry matter for 15 wk after parturition. Four days following a programmed induced ovulation, 5 transvaginal oocyte aspirations were performed 3 or $4 \mathrm{~d}$ apart. Three days after the last aspiration, $\mathrm{PGF}_{2 \alpha}$ was injected, followed $3 \mathrm{~d}$ later by a GnRH injection and a timed artificial insemination (d 0) 16 to $20 \mathrm{~h}$ later. For the first 4 aspirations, oocytes grading 1 or 2 were used for in vitro embryo production. Total cell number and the proportion of terminal deoxynucleotidyl transferase-mediated dUTP nick end labeling (TUNEL)-positive blastomeres were analyzed at $\mathrm{d} 8$. At the fifth aspiration, the occurrence of metaphase II, group II caspase activity, and TUNEL labeling were determined after oocyte maturation. A total of 1,011 oocytes were collected. The proportion of oocytes with high caspase activity was greater for grade 3 compared with grades 1 and 2 (37.5 vs. 1.54 and $1.61 \%)$. Feeding polyunsaturated fatty acids, as compared with monosaturated fatty acids, failed to affect oocyte quality, as demonstrated by subsequent embryo development. Cows fed 18:2- or 18:3-enriched diets had a larger preovulatory follicle at insemination and subsequent volume of the corpus luteum compared with those fed cis $18: 1$ or trans $18: 1$ diets $(16.8,16.2$ vs. $15.0,14.9$ $\pm 0.7 \mathrm{~mm} ; 7,323,8,208$ vs. $6,033,5,495 \pm 644 \mathrm{~mm}^{3}$, respectively). The previously documented benefits of polyunsaturated fatty acids on reproductive performance appear to reflect actions at alternative biological windows in lactating dairy cows.

Key words: fatty acid, embryo, oocyte, cow

Received October 22, 2005

Accepted May 10, 2006.

${ }^{1}$ Corresponding author: thatcher@animal.ufl.edu.

\section{INTRODUCTION}

Dietary supplementation of fat can improve reproductive function of lactating dairy cows. In particular, supplementation of diets with various fat sources varying in concentrations of different fatty acids improves the overall pregnancy rates of cattle. Collectively, these findings support the concept that feeding supplemental fats enhances reproductive performance in cattle. Fat supplementation had beneficial effects on the follicle, oocyte, embryo, and uterus in dairy cattle. However, the precise fatty acids and the mechanisms by which fat supplementation increases the pregnancy rate have yet to be determined.

Fatty acids play an important role in changing the biophysical properties and activity of biological membranes, including fluidity and cell proliferation. Lipids make up a large portion of cellular membranes, and the length of the fatty acid acyl chain, number, and position of double bonds influences membrane properties. Zeron et al. (2001) examined the effects of seasonal changes in fatty acid composition of phospholipids from follicular fluid, granulosa cells, and oocytes collected from dairy cattle in both the summer and winter. The proportions of saturated fatty acids in oocytes and granulosa cells were greater in the summer, and the percentages of monounsaturated (MUFA) and polyunsaturated fatty acids (PUFA) were greater in oocytes and granulosa cells during the winter. Furthermore, relationships were detected between PUFA concentration, embryonic development, and fertility. The PUFA concentration of follicular fluid decreased in the summer in association with a decrease in embryo development and dairy cow fertility. Follicle number, oocyte quality, chilling sensitivity, lipid composition in follicular components, and lipid phase transition in oocytes were examined in ewes fed a diet supplemented with a Ca salt of fish oil for $13 \mathrm{wk}$ (Zeron et al., 2002). The fish oilfed ewes had more follicles and oocytes, better quality oocytes, improved integrity of oocyte membranes, and an increased proportion of long-chain unsaturated fatty acids in plasma and cumulus cells.

Feeding a diet high in Ca salts of palm oil $(800 \mathrm{~g} / \mathrm{d})$ to lactating dairy cows increased the number of blasto- 
cysts produced in vitro following transvaginal ovum pick-up (OPU) compared with a diet low $(200 \mathrm{~g} / \mathrm{d})$ in Ca salts of palm oil (Fouladi-Nashta et al., 2004). In addition, the number of accessory sperm cells attached to the zona pellucida was greater (Cerri et al., 2004). Whether the beneficial effects were due to an enrichment of 18:2 or trans 18:1 or both could not be determined. Collectively, these studies indicate that various fatty acids have differential effects on reproductive responses and can affect oocyte and embryo development. Understanding which fatty acids have beneficial effects on oocyte and embryo development may permit the feeding of diets enriched in certain fatty acid(s) to enhance fertility. The objective of this experiment was to examine the effects of feeding 4 different sources of supplemental fats enriched in either $\mathrm{n}-9$ cis $(\mathbf{1 8 : 1 c}), \mathrm{n}-9$ trans (18:1t), n-6 (18:2), or n-3 (18:3) fatty acids on oocyte quality and follicular development in lactating dairy cows during the summer season.

\section{MATERIALS AND METHODS}

\section{Materials}

The media HEPES-Tyrode's lactate, in vitro fertilization-Tyrode's lactate, and sperm-Tyrode's lactate were purchased from Caisson (Sugar City, ID) and used to prepare HEPES-TALP, IVF-TALP, and sperm-TALP as previously described (Parrish et al., 1986). Oocyte collection medium was TC-199 with Hanks' salts without phenol red (Atlanta Biologicals, Norcross, GA) supplemented with $2 \%$ (vol/vol) bovine steer serum (PelFreez, Rogers, AR) containing $100 \mathrm{U} / \mathrm{mL}$ of heparin, $100 \mathrm{U} / \mathrm{mL}$ of penicillin-G, $0.1 \mathrm{mg} / \mathrm{mL}$ of streptomycin, and $1 \mathrm{~m} M$ glutamine. Oocyte maturation medium was TC-199 (Gibco, Grand Island, NY) with Earle salts supplemented with $10 \%$ (vol/vol) bovine steer serum, 2 $\mu \mathrm{g} / \mathrm{mL}$ of estradiol 17- $\beta, 20 \mu \mathrm{g} / \mathrm{mL}$ of bovine FSH (Folltropin-V; Vetrepharm Canada, London, Ontario, Canada), $22 \mu \mathrm{g} / \mathrm{mL}$ of sodium pyruvate, $50 \mu \mathrm{g} / \mathrm{mL}$ of gentamicin sulfate, and $1 \mathrm{~m} M$ glutamine. Percoll was from Amersham Pharmacia Biotech (Uppsala, Sweden). Frozen semen from various Angus bulls was donated by Southeastern Semen Services (Wellborn, FL). Potassium simplex optimized medium (KSOM) containing $1 \mathrm{mg} / \mathrm{mL}$ of BSA was obtained from Caisson. On the day of use, KSOM was modified for bovine embryos to produce KSOM-BE2 (Soto et al., 2003). Essentially fatty acid-free BSA was from Sigma (St. Louis, MO) and fetal bovine serum was obtained from Atlanta Biologicals.

The In Situ Cell Death Detection Kit (tetramethyl rhodamine red) was obtained from Roche (Indianapolis, IN). Hoechst 33258 and glycerol were purchased from Sigma. Polyvinylpyrrolidone (PVP) was purchased from Eastman Kodak (Rochester, NY) and RQ1 RNase- free DNase was from Promega (Madison, WI). All other reagents were purchased from Sigma or Fisher Scientific (Pittsburgh, PA).

\section{Cows and Experimental Diets}

The experiment was conducted at the University of Florida Dairy Research Unit (Hague, FL) during the months of May 2004 through November 2004. All experimental cows were managed according to the guidelines approved by the University of Florida Animal Care and Use Committee. Primiparous $(\mathrm{n}=22)$ and multiparous $(\mathrm{n}=32)$ Holstein cows in late gestation were assigned randomly after stratification of multiparous cows by previous mature milk equivalent and primiparous cows by BW. There were no differences in BCS at calving among groups. Before calving, cows were housed in sodbased pens and fed individually utilizing shaded Calan gates (American Calan Inc., Northwood, NH) beginning 5 wk before expected calving. Upon calving, cows were moved to a free-stall barn with fans, sprinklers, and Calan gates. All cows received their respective dietary treatment at least $3 \mathrm{wk}$ before the actual calving date and continuing until approximately 107 DIM. The 4 diets, each enriched with a different omega fatty acid, were as follows: 1) high-oleic sunflower oil (Trisun; Humko Oil, Memphis, TN) enriched in n-9 cis (18:1c; $\mathrm{n}=8$ multiparous cows and 6 primiparous cows), 2) $\mathrm{Ca}$ salts of trans fatty acids (Virtus Nutrition, Fairlawn, $\mathrm{OH}$ ) enriched in $\mathrm{n}-9$ trans (18:1t; $\mathrm{n}=8$ multiparous cows and 6 primiparous cows), 3) Ca salts of palm and soybean oil (Megalac-R; Church \& Dwight Co., Princeton, NJ) enriched in n-6 (18:2; $\mathrm{n}=8$ multiparous cows and 5 primiparous cows), or 4) linseed oil (Archer Daniels Midland, Red Wing, MN) enriched in n-3 (18:3; $\mathrm{n}=8$ multiparous cows and 5 primiparous cows). Fats were fed at $1.35 \%$ of dietary DM beginning at $5 \mathrm{wk}$ before the expected calving date and at 1.5\% (oils) and $1.75 \%$ (Ca salts) of dietary DM for 15 wk after parturition. Postpartum diets were isolipid because Ca constitutes about $85 \%$ of the Ca salt mixture. The fatty acid composition of the 4 fat sources is given in Table 1 . Diets were formulated to meet or exceed NRC (2001) recommendations for either late-gestation or early-lactation Holstein cows that weighed $650 \mathrm{~kg}$ and produced $35 \mathrm{~kg}$ of $3.5 \%$ FCM. Prepartum diets were formulated to have a cation-anion difference of $-9 \mathrm{mEq} / 100 \mathrm{~g}$ (DM basis). The basal ingredient composition of the prepartum diets was corn silage, bermudagrass hay, ground corn, citrus pulp, soybean meal, trace mineralized salt, and a mineral-vitamin premix. The basal ingredient composition of the postpartum diets was corn silage, alfalfa hay, ground corn, citrus pulp, cottonseed hulls, SoyPlus (West Central Soy, Ralston, IA), soybean meal, 
Table 1. Percentage of fatty acids from the total fatty acids in the supplemental fat sources ${ }^{1}$

\begin{tabular}{lllll}
\hline & \multicolumn{4}{c}{ Treatment } \\
\cline { 2 - 5 } Fatty acid & $\begin{array}{l}\text { High-oleic } \\
\text { sunflower oil }\end{array}$ & $\begin{array}{l}\text { Ca salts } \\
\text { of trans } \\
\text { fatty acids }\end{array}$ & $\begin{array}{l}\text { Ca salts } \\
\text { of palm and } \\
\text { soybean oil }\end{array}$ & $\begin{array}{l}\text { Linseed } \\
\text { oil }\end{array}$ \\
\hline $14: 0$ & - & 0.3 & 0.9 & - \\
$16: 0$ & 4.6 & 15.0 & 36.3 & - \\
$16: 1$ & - & 0.1 & - & - \\
$17: 0$ & - & 0.1 & 0.1 & 3.2 \\
$18: 0$ & - & 8.3 & 0.6 & 19.6 \\
$18: 1$ trans & 78.8 & 1.0 & 26.1 & 16.0 \\
$18: 1$ cis & 13.7 & 2.0 & 28.5 & - \\
CLA & - & 0.2 & 0.5 & - \\
cis-9,trans-11 & - & - & 0.1 & 55.2 \\
trans-10,cis-12 & 0.2 & - & 3.0 & \\
18:3 & & & &
\end{tabular}

${ }^{1}$ Data are the percentage of total fatty acids (wt/wt). CLA = conjugated linoleic acid.

and a mineral-vitamin premix. All diets were formulated for $1.74 \mathrm{Mcal}$ of $\mathrm{NE}_{\mathrm{L}} / \mathrm{kg}, 15.3 \% \mathrm{CP}$, and $34.5 \%$ NDF (DM basis).

Concentrate mixtures and forage sources were mixed in a weighing and mixing unit (American Calan, Inc.) and offered twice daily to allow 5 to $10 \%$ orts (as-fed basis). Calan gates were used to monitor the individual feed intake of cows. Orts from each diet were collected once daily and weighed. The DM concentration of silage was monitored once weekly $\left(55^{\circ} \mathrm{C}\right.$ for $48 \mathrm{~h}$ ) to maintain the proper forage-to-concentrate ratio of the diets. Cows were milked thrice daily, and calibrated electronic milk meters were used at each milking to record milk weights. The BCS and BW were assessed weekly by the same individual.

\section{Fatty Acid Analysis of Dietary Fat Supplements}

The fat extraction and the methylation procedure for the dietary fat supplements (100 $\mathrm{mg}$ of fresh weight) followed the procedures described by Kramer et al. (1997). Lipids were extracted by adding $2 \mathrm{~mL}$ of sodium methoxide (Acros Organics, Morris Plains, NJ), vortexing, and incubating in a $50^{\circ} \mathrm{C}$ water bath for 10 $\min$. The tubes were removed from the water bath and allowed to cool for $5 \mathrm{~min}$. Three milliliters of $5 \%$ methanolic $\mathrm{HCl}$ (Fisher Scientific, Hampton, NH) was added and the tubes were vortexed. The tubes were incubated in an $80^{\circ} \mathrm{C}$ water bath for $10 \mathrm{~min}$, removed from the water bath, and allowed to cool for $7 \mathrm{~min}$. One milliliter of hexane and $7.5 \mathrm{~mL}$ of $6 \% \mathrm{~K}_{2} \mathrm{CO}_{3}$ were added. The tubes were vortexed, centrifuged at $194 \times g$ for $5 \mathrm{~min}$, and the upper layer was separated into $10-\mathrm{mL}$ glass tubes. The solvent was completely evaporated under $\mathrm{N}$ gas, $100 \mu \mathrm{L}$ of hexane was added to redissolve the methylated fatty acids, and the solution transferred to a GLC vial.

Fatty acid methyl esters were determined using a Varian CP-3800 gas chromatograph (Varian Inc., Palo Alto, CA) equipped with autosampler (Varian CP-8400), flame ionization detector, and a Varian capillary column (CP-Sil 88, $100 \mathrm{~m} \times 0.25 \mathrm{~mm} \times 0.2 \mu \mathrm{m})$. The carrier gas was He, the split ratio was 10:1, and the injector and detector temperatures were maintained at 230 and $250^{\circ} \mathrm{C}$, respectively. One microliter of sample was injected through the autosampler into the column. The oven temperature was initially set at $120^{\circ} \mathrm{C}$ for $1 \mathrm{~min}$, increased by $5^{\circ} \mathrm{C} / \mathrm{min}$ up to $190^{\circ} \mathrm{C}$, held at $190^{\circ} \mathrm{C}$ for 30 min, increased by $2^{\circ} \mathrm{C} / \mathrm{min}$ up to $220^{\circ} \mathrm{C}$, and held at $220^{\circ} \mathrm{C}$ for $40 \mathrm{~min}$. The peak was identified and calculated based on the retention time and peak area of known standards.

\section{Synchronization for OPU and Timed AI}

Multiparous and primiparous cows were grouped on a weekly basis and synchronized for OPU using a modified Ovsynch protocol. An injection (100 $\mu \mathrm{g}$, i.m.) of GnRH (Cystorelin; Merial, Athens, GA) was administered along with the insertion of a controlled internal drug-releasing device (CIDR; CIDR-B, Pharmacia, Kalamazoo, MI; $1.38 \mathrm{~g}$ of progesterone) at $47 \pm 3 \mathrm{DIM}$, followed $7 \mathrm{~d}$ later by an injection $\left(25 \mathrm{mg}\right.$, i.m.) of $\mathrm{PGF}_{2 \alpha}$ (Lutalyse; Pfizer, Kalamazoo, MI.) and removal of the CIDR insert (Figure 1). Approximately $48 \mathrm{~h}$ following $\mathrm{PGF}_{2 \alpha}$, a second injection of GnRH (56 DIM) was administered to induce ovulation at 57 DIM. Beginning at 4 $\mathrm{d}$ following the second $\mathrm{GnRH}$ injection ( $3 \mathrm{~d}$ following ovulation), OPU was conducted every 3 to $4 \mathrm{~d}$ for 5 consecutive sessions $(60,63,66,69$, and 72 DIM or d 


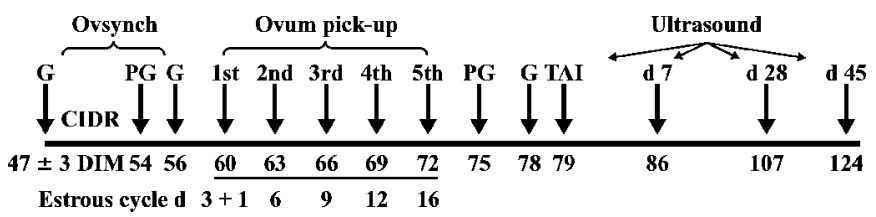

Figure 1. Experimental protocol illustrating the DIM for synchronization injections, ultrasonography, ovum pick-up, and timed artificial insemination (TAI; d 0). $\mathrm{G}=\mathrm{GnRH} ; \mathrm{PG}=\mathrm{PGF}_{2 \alpha} ; \mathrm{CIDR}=$ controlled internal drug releasing insert containing $1.38 \mathrm{~g}$ of progesterone.

$3,6,9,12$, and 16 of the synchronized estrous cycle; Figure 1).

Timed artificial insemination (TAI) was conducted as follows. An injection of $\mathrm{PGF}_{2 \alpha}$ was given $3 \mathrm{~d}$ following the last OPU session (75 DIM). An injection of GnRH (100 $\mu$ g, i.m.) was given $72 \mathrm{~h}$ later (78 DIM), and all cows were inseminated at approximately 16 to $20 \mathrm{~h}$ after injection of $\mathrm{GnRH}$. All cows were inseminated (79 DIM) with semen from 1 Holstein bull of good fertility. All cows were injected $(500 \mathrm{mg}$ ) with bST (Posilac; Monsanto Co., St. Louis, MO) at AI and every 2 wk thereafter. The bST injections were given s.c. in the space between the ischium and tail head.

\section{Blood Collections and Temperature Measurements}

Blood samples $(7 \mathrm{~mL})$ were collected just prior to all synchronization injections (d 47 $\pm 3,54,56,75,78 \mathrm{DIM})$, prior to each OPU session (d 60,63, 66, 69, and 72 DIM), and on d 7 following AI (d 0). Blood samples were collected using 20-gauge Vacutainer blood collection needles (Becton Dickinson and Co., Franklin Lakes, NJ) from a coccygeal blood vessel in 3 different locations, which were rotated at each bleeding to minimize irritation. Samples were collected into evacuated heparinized tubes (Vacutainer; Becton Dickinson, East Rutherford, NJ). Immediately following sample collection, blood was stored on ice until centrifugation (3000 $\times g$ for 20 min at $4^{\circ} \mathrm{C}$ ) and separation and storage of plasma within $6 \mathrm{~h}$. Plasma was stored at $-20^{\circ} \mathrm{C}$ until assayed for progesterone, growth hormone (GH), IGFI, and insulin. Rectal temperatures were recorded prior to each OPU session.

\section{Ultrasonography and OPU Procedure}

Ovaries were evaluated by real-time ultrasonography (Aloka SSD-500; Aloka Co. Ltd., Tokyo, Japan) with a $5-\mathrm{MHz}$ linear-array transrectal transducer at 54 and 56 DIM during synchronization for OPU, at 75 and 78 DIM during synchronization for AI, at 79 DIM for AI, at ovulation at 86 DIM, and at 107 and 124 DIM for d
28 and 45 pregnancy diagnoses, respectively. Pregnancy rate was defined as the number of cows confirmed pregnant based on ultrasonography of fetal heartbeat divided by the number of cows inseminated. An ovarian map was made to record the location and size of the tissue volume $\left(\mathrm{mm}^{3}\right)$, number of corpora lutea $(\mathbf{C L})$, and the largest follicle $(\mathrm{mm})$. The volume of CL tissue was calculated using the following equation: volume $=$ $1.333 \times \pi \times$ radius $^{3}$, where radius $=($ length $/ 2+$ width $/$ $2) / 2$. For CL with a fluid-filled cavity, the volume of the cavity was calculated and subtracted from the total volume of the CL.

At the time of OPU, cows were restrained in a squeeze chute and given anesthesia via a caudal epidural injection of $5 \mathrm{~mL}$ of $2 \%$ lidocaine (AgTech Inc., Manhattan, KS) to provide relaxation to the rectovaginal region. Follicles were aspirated with the aid of an Aloka 500 portable ultrasound scanner equipped with a needle guide and connected to a $5-\mathrm{MHz}$ vaginal sector transducer probe. The 4-cm 17-gauge needle (COOK, Queensland, Australia) with echogenic tip was connected to a regulated vacuum pump (Pioneer Medical Inc., Melrose, MA), which created a constant vacuum pressure of $75 \mathrm{~mm}$ of $\mathrm{Hg}$ with an aspiration rate of 14 $\mathrm{mL} / \mathrm{min}$ when the foot pedal was activated. For each cow, in each OPU session, the number of visibly aspirated follicles and size and number of CL were recorded. Follicular contents from all visible 3 - to $12-\mathrm{mm}$ follicles were collected into a single $50-\mathrm{mL}$ conical tube containing 10 to $15 \mathrm{~mL}$ of oocyte collection medium.

Following OPU, the aspirate from each donor cow was filtered through a $100-\mu \mathrm{m}$ cell strainer into a Petri dish. The Petri dish was searched with a dissecting microscope for cumulus oocyte complexes (COC). Recovered COC were graded on a scale of 1 to 3 with the following criteria: grade $1=3$ or more layers of cumulus cells with a homogeneous ooplasm uniform in size, color, and texture; grade $2=1$ to 3 layers of cumulus cells with a homogeneous or slightly degenerated ooplasm; grade 3 = completely degenerated ooplasm, expanded cumulus cells, or denuded.

For the first 4 OPU sessions, grades 1 and 2 COC from each individual donor were washed 3 times in oocyte collection medium and placed into 2 -mL microcentrifuge tubes containing approximately $2 \mathrm{~mL}$ of oocyte maturation medium that had been prewarmed and equilibrated at $38.5^{\circ} \mathrm{C}$ in $5 \% \mathrm{CO}_{2}$ in humidified air. For the fifth OPU session, grades 1,2 , and 3 COC were selected and processed as described above except that COC from each individual donor were also separated by grade. The tubes containing the collected oocytes were placed into a portable incubator (Minitube, Verona, WI) warmed to $39^{\circ} \mathrm{C}$ and held at the farm until collections from all donor cows were complete $(>3 \mathrm{~h})$. 
Following the collection from all donor cows, COC were transported to the laboratory.

\section{In Vitro Production of Embryos from Oocytes Collected by OPU}

Embryos were produced in vitro as described previously for our laboratory (Soto et al., 2003). Upon arrival at the laboratory, COC were washed 3 times in oocyte maturation medium and placed into $50-\mu \mathrm{L}$ drops of oocyte maturation medium ( 1 to 5 COC per drop) overlaid with mineral oil. The recovered COC were allowed to mature for 21 to $24 \mathrm{~h}$ at $38.5^{\circ} \mathrm{C}$ in $5 \% \mathrm{CO}_{2}$ in humidified air. Following maturation, $\mathrm{COC}$ from the fifth aspiration were denuded of cumulus cells by vortexing in HEPES-TALP containing 1,000 units/mL of hyaluronidase type IV for $5 \mathrm{~min}$. After vortexing, denuded oocytes were processed as described below for the assessment of meiotic maturation, caspase activity, and terminal deoxynucleotidyl transferase-mediated dUTP nick end labeling (TUNEL).

For the first 4 OPU aspirations, COC were washed once in HEPES-TALP after maturation and placed in their respective groups in 4 -well plates ( 1 to 5 oocytes per well) containing $600 \mu \mathrm{L}$ of IVF-TALP per well. Semen from 3 random Angus bulls was Percoll-purified (Parrish et al., 1986) and added to each well at a concentration of $1 \times 10^{6}$ spermatozoa $/ \mathrm{mL}$. Following the addition of sperm, $25 \mu \mathrm{L}$ of a solution of $0.5 \mathrm{mM}$ penicillamine, $0.25 \mathrm{~m} M$ hypotaurine, and $25 \mu M$ epinephrine in $0.9 \%$ (wt/vol) $\mathrm{NaCl}$ was added per well. Sperm and $\mathrm{COC}$ were coincubated for $8 \mathrm{~h}$ at $38.5^{\circ} \mathrm{C}$ in $5 \% \mathrm{CO}_{2}$ in humidified air. After coincubation, putative zygotes were denuded of cumulus cells by suspending them in HEPES-TALP medium containing 1,000 units/mL of hyaluronidase type IV and vortexing for $5 \mathrm{~min}$.

Following vortexing, presumptive zygotes were washed 3 times in HEPES-TALP and once in KSOMBE2. Presumptive zygotes were then placed into 22.5$\mu \mathrm{L}$ culture drops of KSOM-BE2 ( 1 to 5 oocytes per drop). Oocytes were cultured at $38.5^{\circ} \mathrm{C}$ in $5 \% \mathrm{O}_{2}, 5 \% \mathrm{CO}_{2}$, and $90 \% \mathrm{~N}_{2}$ in humidified air until d 8 postinsemination. The proportion of oocytes that cleaved as well as the proportion of embryos at either the 2- to 3-, 4- to 7-, or $>8$-cell stage were recorded at $\mathrm{d} 3$ postinsemination and $2.5 \mu \mathrm{L}$ of fetal calf serum (to a final concentration of $10 \% \mathrm{vol} / \mathrm{vol}$ ) was added to each culture drop. The proportion of oocytes that developed to the morulae (compacted cell mass), early blastocyst (rudimentary blastocoel cavity), blastocyst (fully formed blastocoel cavity), and advanced blastocyst stages such as expanded (thinned zona pellucida with stretched blastocoel cavity), hatching (zona pellucida breaks and the blastocyst begins to protrude), or hatched (empty zona pellucida with free blastocyst) were recorded on d 8 postinsemination. The TUNEL assay was performed, and the number of cells was counted on all morulae and blastocysts.

\section{In Vitro Production of Embryos from Ovaries Collected from an Abattoir}

During the same months as the OPU aspirations, ovaries from Holstein and non-Holstein cows were obtained from a local abattoir (approximately $1.5 \mathrm{~h}$ from the laboratory) and transported to the laboratory in $0.9 \%$ (wt/vol) $\mathrm{NaCl}$ at room temperature. The ovaries were sliced and COC were collected into a beaker containing oocyte collection medium (which contained $2 \mathrm{U} /$ $\mathrm{mL}$ of heparin). All grades 1 and $2 \mathrm{COC}$ were separated by breed and matured, fertilized, and cultured as described above for OPU oocytes.

\section{Group II Caspase Activity}

Group II caspase activity (i.e., caspase 2, 3, and 7) was measured based on cleavage of a synthetic substrate specific for group II caspases (those recognizing the AA motif DEXD) and the resultant emission of green fluorescence. Denuded oocytes were washed 3 times in $50-\mu \mathrm{L}$ drops of prewarmed HEPES-TALP. Oocytes were then incubated in 25- $\mu \mathrm{L}$ microdrops of HEPES-TALP containing $5 \mu M$ of PhiPhiLux- $\mathrm{G}_{1} \mathrm{D}_{2}$ (OncoImmunin, Inc., Gaithersburg, MD) at $39^{\circ} \mathrm{C}$ for $40 \mathrm{~min}$ in the dark. Negative controls (oocytes recovered from the abattoir) were incubated in HEPES-TALP only. Following incubation, oocytes were washed 3 times in $50-\mu \mathrm{L}$ drops of HEPES-TALP and placed on 2-well glass slides containing $100 \mu \mathrm{L}$ of prewarmed HEPES-TALP. Fluorescence was observed using a Zeiss Axioplan 2 epifluorescence microscope (Zeiss, Göttingen, Germany). Digital images were acquired using AxioVision software (Zeiss) and a high-resolution black-and-white Zeiss AxioCam MRm digital camera.

\section{TUNEL Assay, Assessment of Total Cell Number, and Progression to Metaphase II}

The TUNEL assay was used to detect DNA fragmentation associated with late stages of the apoptotic cascade as described previously (Jousan and Hansen, 2004). Embryos were removed from KSOM-BE2 and washed 3 times in $50-\mu \mathrm{L}$ drops of $10 \mathrm{mM} \mathrm{KPO}_{4}, \mathrm{pH}$ 7.4, containing $0.9 \%$ (wt/vol) $\mathrm{NaCl}(\mathrm{PBS})$ and $1 \mathrm{mg} / \mathrm{mL}$ of PVP (PBS-PVP) by transferring the embryos from drop to drop. Zona pellucida-intact embryos and oocytes (after measurement of caspase activity as described above) were fixed in a $50-\mu \mathrm{L}$ drop of $4 \%$ (wt/vol) paraformaldehyde in PBS for 15 min at room temperature, 
washed 3 times in PBS-PVP, and stored in $500 \mu \mathrm{L}$ of PBS-PVP at $4^{\circ} \mathrm{C}$ until the time of assay. All steps of the TUNEL assay were conducted using microdrops in a humidified box.

On the day of the TUNEL assay, embryos and oocytes were transferred to a 50- $\mu \mathrm{L}$ drop of PBS-PVP and then permeabilized in $0.1 \%$ (vol/vol) Triton X-100 containing $0.1 \%(\mathrm{wt} / \mathrm{vol})$ sodium citrate for $10 \mathrm{~min}$ at room temperature. Positive controls for the TUNEL assay (oocytes from ovaries obtained at the abattoir) were incubated in $50 \mu \mathrm{L}$ of RQ1 RNase-free DNase $(50 \mathrm{U} / \mathrm{mL})$ at $37^{\circ} \mathrm{C}$ in the dark for $1 \mathrm{~h}$. Positive controls and treated oocytes and embryos were washed in PBS-PVP and incubated in $25 \mu \mathrm{L}$ of TUNEL reaction mixture containing tetramethyl rhodamine red conjugated dUTP and the enzyme terminal deoxynucleotidyl transferase (as prepared following the guidelines of the manufacturer) for $1 \mathrm{~h}$ at $37^{\circ} \mathrm{C}$ in the dark. Negative controls were incubated in the absence of terminal deoxynucleotidyl transferase. Oocytes and embryos were then washed 3 times in PBS-PVP and incubated in a $25-\mu \mathrm{L}$ drop of Hoechst $33258(1 \mu \mathrm{g} / \mathrm{mL})$ for $15 \mathrm{~min}$ in the dark. Oocytes and embryos were washed 3 times in PBS-PVP to remove excess Hoechst 33258 and mounted on 10\% (wt/ vol) poly-L-lysine-coated slides in glycerol. Total cell number (embryos), completion of metaphase II (oocytes; based on observation of 2 polar bodies), and TUNELpositive nuclei (embryos and oocytes) were assessed using a Zeiss Axioplan 2 epifluorescence microscope (Zeiss). Digital images were acquired using AxioVision software (Zeiss) and a high-resolution black and white Zeiss AxioCam MRm digital camera.

\section{Statistical Analysis}

All oocyte and embryo responses were analyzed using the GLIMMIX procedure of SAS (SAS Institute, Cary, NC). The model included treatment (18:1c, 18:1t, 18:2, and 18:3), parity (primiparous and multiparous), and experimental day (d 3, 6, 9, and 12) with the higher order interactions. If the higher order interactions were not significant, they were removed from the model. Cow within treatment or cow within treatment by parity were random effects specified in the models. The covariance structure used was an autoregressive order 1 . Predesigned orthogonal contrasts were used to make comparisons between groups of treatments. A maximum of 50 was used for the number of iterations performed to meet convergence criteria. An error statement was used to specify the data distribution as either Poisson for continuous nonnormally distributed data and binomial for discreet nonnormally distributed data. Also, a link statement was used to specify that a log calculation was used for a Poisson distribution and logit for a binomial distribution.

Pregnancy rates, maturation to metaphase II, group II caspase activity, and TUNEL analysis from oocytes collected on the fifth OPU session were analyzed using the logistic regression procedure of SAS to examine the main effects of treatment, parity, and treatment by parity interaction.

During the OPU aspirations, progesterone concentration, number of CL and follicles, and CL tissue volume were analyzed using the mixed-model procedure of SAS. This procedure applies methods based on the mixed model with a special parametric structure on the covariance matrices. The data set was tested to determine the covariance structure that provided the best fit for the data. Covariance structures tested included compound symmetry, autoregressive order 1 , and unstructured. The covariance structure used was autoregressive order 1 . Cow within treatment by parity interaction was specified as a random effect in the model. The model consisted of treatment, parity, and day with the higher order interactions. If the higher order interactions were not significant, they were removed from the model. The CL tissue volume was adjusted using the CL number as a covariate.

Size of the largest follicle on d 0 and 7, CL number and volume on $\mathrm{d} 7$, and plasma progesterone concentration on $\mathrm{d} 7$ following TAI were analyzed using the GLM procedure of SAS. The main effects of treatment (18:1c, 18:1 $t, 18: 2$, and 18:3), parity, and the interaction of treatment by parity were examined with the number of CL used as a covariate for CL volume. Predesigned orthogonal contrasts were used to make comparisons between groups of treatments.

\section{RESULTS}

\section{DMI, BW, and Milk Yield}

There were no differences among treatments for individual DMI prepartum $(8.8,9.2,8.7$, and $9.4 \pm 0.5 \mathrm{~kg} /$ d) and postpartum $(16.6,16.2,15.8$, and $16.6 \pm 0.6 \mathrm{~kg} /$ d), milk yield (34.5, 34.7, 32.2, and $34.0 \pm 1.4 \mathrm{~kg} / \mathrm{d})$, BW postpartum $(586,575,555$, and $558 \pm 15 \mathrm{~kg})$, and BCS postpartum (3.13, 3.25, 2.92, and $3.06 \pm 0.11$ ) for diets enriched in 18:1c, 18:1 $t, 18: 2$, and 18:3 fatty acids, respectively.

\section{Follicle and Oocyte Responses to Different Diets}

Body temperatures and number of follicles aspirated per cow were not different among treatment groups (Table 2). More visible follicles were aspirated in primiparous compared with multiparous cows (4.2 vs. 5.1 \pm 0.3 , respectively; $P<0.01$ ). A total of $316,236,191$, 
Table 2. Means of body temperature, follicular responses, and oocyte responses of lactating multiparous and primiparous cows fed diets enriched in either 18:1 cis $(\mathrm{n}=14), 18: 1$ trans $(\mathrm{n}=14), 18: 2(\mathrm{n}=13)$, or $18: 3(\mathrm{n}=13)^{1}$

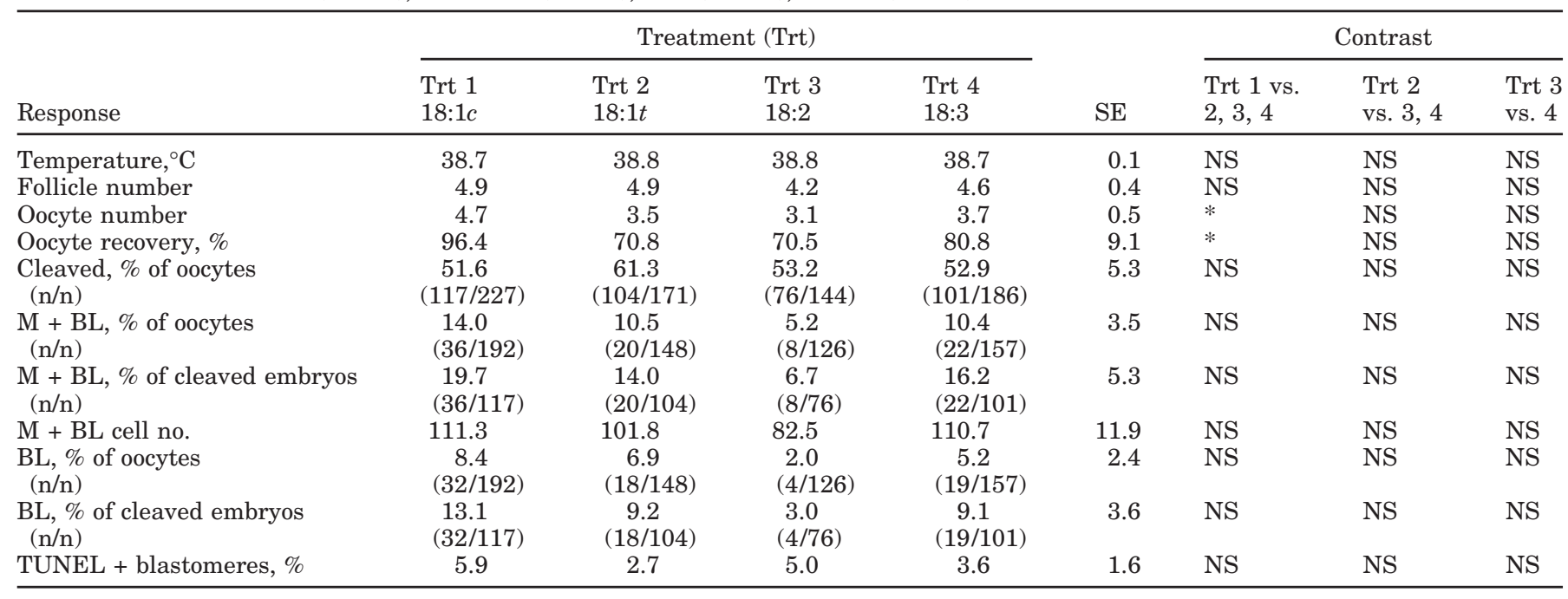

${ }^{1}$ Data outside parentheses represent model-based means and pooled SE from the appropriate analyses described in the statistical methods. Data inside parentheses represent the fraction of follicles that yielded a recoverable oocyte (recovery), or the fraction of oocytes or cleaved embryos that became morulae (M) or blastocysts (BL) or both. NS = not significant.

$* P<0.05$

and 268 oocytes were collected from cows fed diets enriched in 18:1c, 18:1t, 18:2, and 18:3 fatty acids, respectively. An average of $4.6 \pm 0.4$ follicles per cow were aspirated, with $3.7 \pm 0.3$ oocytes per cow recovered $(80 \%)$. More oocytes were collected $(P<0.05)$ and the recovery rate was greater $(P<0.05)$ from cows fed $18: 1 c$ than other fat sources (Table 2). Of the oocytes collected, no interaction was detected between diet and grade for the distribution of oocytes graded 1,2 , or 3 . The average proportion of oocytes graded 1,2 , or 3 across diets was $36.5 \%$ (77/211), 49.8\% (105/211), and $13.7 \%$ (29/211), respectively.

Diet did not affect the cleavage rate (52 to $62 \%$; Table 2 ) or the stage of embryonic development at $d 3$. The proportion of oocytes that became morulae or blastocysts (5 to 14\%) and the proportion of oocytes that became blastocysts (2 to $8 \%$ ) were not different among treatment groups (Table 2). The numbers of blastomeres in morulae and blastocysts on $\mathrm{d} 8$ were not different among treatment groups. Oocytes from primiparous cows tended $(P<0.10)$ to result in embryos with a reduced number of TUNEL-positive cells compared with oocytes from multiparous cows ( 3.1 vs. $5.5 \pm 1.2$, respectively).

\section{Follicle and Oocyte Responses to Different Days of the Estrous Cycle}

The number of visible follicles was greater $(P<0.01)$ on $\mathrm{d} 3$ following induced ovulation compared with all other days of aspiration (Table 3). The number of oocytes collected was also greater $(P<0.01)$ on $\mathrm{d} 3$ and 6 than on $\mathrm{d} 9$ and 12 (Table 3). However, the recovery rate was greater $(P<0.05)$ for d 6 compared with $\mathrm{d} 9$ and 12 (Table 3). There was no interaction between oocyte grade and day of the estrous cycle on the distribution of oocytes that were graded 1,2 , or 3 . The percentage of cleaved embryos tended to be greater $(P<0.10)$ on both d 3 and 6 compared with d 9 and 12 (Table 3 ).

\section{Oocyte Quality for the Fifth OPU Session}

On the fifth OPU session, 151 oocytes were collected and the proportion exhibiting caspase activity, TUNELpositive cells, and progression to metaphase II was determined. Diet had no influence on the percentage of oocytes with caspase activity $[9.4 \%(3 / 32), 7.7 \%(2 / 26)$, $9.1 \%(5 / 55)$, and $2.6 \%$ (1/38), respectively], percent TUNEL-positive cells [33.3\% (10/30), 8.3\% (2/24), 7.3\% (4/ $55)$, and $18.9 \%$ (7/37), respectively), or the percent that progressed to metaphase II [65.5\% (19/29), 77.8\% (14/ 18), $76.9 \%$ (40/52), and $80.6 \%$ (29/36), respectively]. However, the percentage of oocytes with caspase activity was decreased $(P<0.01)$ in grades 1 and 2 compared with grade 3 , and the percent that matured to metaphase II was increased in grades 1 and 2 compared with grade 3 (Table 4). No difference was detected among grades for the percent of oocytes that were TUNEL positive (Table 4). 
Table 3. Means of follicular and embryonic responses of lactating multiparous and primiparous cows fed diets enriched in either 18:1 cis $(n=14), 18: 1$ trans $(n=14), 18: 2(n=13)$, or 18:3 $(n=13)$, and transvaginally aspirated on $\mathrm{d} 3,6,9$, and 12 of a synchronized estrous cycle ${ }^{1}$

\begin{tabular}{|c|c|c|c|c|c|c|c|c|}
\hline \multirow[b]{3}{*}{ Response } & \multirow{2}{*}{\multicolumn{4}{|c|}{ Day of estrous cycle \pm 1}} & \multirow[b]{3}{*}{$\mathrm{SE}$} & \multicolumn{3}{|c|}{ Contrast } \\
\hline & & & & & & 3 vs. & 6 vs. & $9 \mathrm{vs}$. \\
\hline & 3 & 6 & 9 & 12 & & $6,9,12$ & 9,12 & 12 \\
\hline Follicle number & 5.3 & 4.6 & 4.1 & 4.5 & 0.3 & $* *$ & NS & NS \\
\hline Oocyte number & 4.7 & 4.1 & 3.2 & 3.0 & 0.4 & $* *$ & $* *$ & NS \\
\hline Oocyte recovery, \% & 87.8 & 88.4 & 75.4 & 66.5 & 7.5 & NS & $*$ & NS \\
\hline $\begin{array}{l}\text { Cleaved, } \% \text { of oocytes } \\
(\mathrm{n} / \mathrm{n})\end{array}$ & $\begin{array}{c}60.6 \\
(135 / 224)\end{array}$ & $\begin{array}{c}58.3 \\
(113 / 195)\end{array}$ & $\begin{array}{l}47.7 \\
(71 / 154)\end{array}$ & $\begin{array}{l}52.4 \\
(79 / 155)\end{array}$ & 6.2 & $\dagger$ & $\dagger$ & NS \\
\hline
\end{tabular}

${ }^{1}$ Data outside of parentheses represent model-based means and pooled SE from the appropriate analyses described in the statistical methods. Data in parentheses represent the fraction of cleaved embryos from total oocytes. NS = not significant.

$\dagger P<0.10, * P<0.05,{ }^{*} * P<0.01$.

\section{Internal IVF Control from Slaughterhouse Ovaries}

Holstein ( $\mathrm{n}=115)$ and non-Holstein $(\mathrm{n}=112)$ oocytes were collected from slaughterhouse ovaries, and those of grades 1 and 2 were fertilized in vitro. Breed had no effect on the proportion of oocytes that had cleaved [nonHolstein $78.9 \pm 6.7 \%$ (88/112) vs. Holstein $68.0 \pm 6.7 \%$ (76/115)] by d 3 . At d 3 postinsemination, the proportion of cleaved embryos that had reached the $>8$-cell stage tended to be greater (breed by stage interaction, $P<$ $0.10)$ from non-Holstein oocytes than from Holstein oocytes (Figure 2). The percentage of oocytes that had become blastocysts by d 8 tended to be reduced $(P<$ $0.10)$ for Holstein oocytes [21.2 $\pm 11.4 \%$ (22/115)] as compared with non-Holstein oocytes [35.1 $\pm 12.3 \%$ (41/ 112)]. There was no breed difference in the proportion of cleaved embryos that were blastocysts on d 8 [nonHolstein $=40.2 \pm 15.0 \%$ (41/88) vs. Holstein $=33.3 \pm$ $14.9 \%(22 / 76)]$. However, the stage of blastocyst development was more advanced $(P<0.05)$ in the non-Holsteins (Figure 3).

\section{Progesterone, Ovarian, and Pregnancy Responses}

No difference in plasma concentrations of progesterone was detected among treatments at $47 \pm 3$ DIM (at the start of synchronization; $3 \pm 0.7 \mathrm{ng} / \mathrm{mL}$ ) or during each OPU session $(4 \pm 0.4 \mathrm{ng} / \mathrm{mL})$. Diet did not influence CL number $(1 \pm 0.1)$ or CL volume $\left(6,818 \pm 392 \mathrm{~mm}^{3}\right)$. However, primiparous cows had fewer CL than multiparous cows ( 0.9 vs. $1.2 \pm 0.1)$ during the first 4 OPU aspirations. As expected, the main effect of day was detected $(P<0.01)$, with both CL volume and progesterone concentrations increasing during the luteal phase when examined at $\mathrm{d} 3,6,9,12$, and 16 following a synchronized estrus (CL volume: 3,018, 8,098, 10,525, 10,255 , and $10,590 \pm 540 \mathrm{~mm}^{3}$, respectively; progesterone: $1.1,2.4,4.7,5.5$, and $6.2 \pm 0.3 \mathrm{ng} / \mathrm{mL}$, respectively). At AI, the largest follicle was increased $(P<0.05)$ in cows fed diets enriched in 18:2 or 18:3 (Table 5). Subsequently, CL volume was larger $(P<0.05)$ in cows fed these same diets (Table 5). However, diet did not influence the concentrations of plasma progesterone on $\mathrm{d} 7$

Table 4. Mean oocyte quality responses from lactating multiparous and primiparous cows fed diets enriched in either $18: 1$ cis $(\mathrm{n}=14), 18: 1$ trans $(\mathrm{n}=14), 18: 2(\mathrm{n}=13)$, or $18: 3(\mathrm{n}=13)^{1}$

\begin{tabular}{|c|c|c|c|c|c|}
\hline \multirow[b]{2}{*}{ Response } & \multicolumn{3}{|c|}{ Grade of oocytes } & \multicolumn{2}{|c|}{ Contrast } \\
\hline & 1 & 2 & 3 & 1 vs. 2,3 & 2 vs. 3 \\
\hline $\begin{array}{l}\text { Caspase activity, } \% \\
(\mathrm{n} / \mathrm{n})\end{array}$ & $\begin{array}{l}1.5 \\
(1 / 65)\end{array}$ & $\begin{array}{l}1.6 \\
(1 / 62)\end{array}$ & $\begin{array}{l}37.5 \\
(9 / 24)\end{array}$ & $*$ & $* *$ \\
\hline $\begin{array}{l}\text { TUNEL labeling, \% } \\
(\mathrm{n} / \mathrm{n})\end{array}$ & $\begin{array}{l}14.5 \\
(9 / 62)\end{array}$ & $\begin{array}{l}13.6 \\
(8 / 59)\end{array}$ & $\begin{array}{l}24.0 \\
(6 / 25)\end{array}$ & NS & NS \\
\hline $\begin{array}{l}\text { Metaphase II, \% } \\
(\mathrm{n} / \mathrm{n})\end{array}$ & $\begin{array}{l}76.3 \\
(45 / 59)\end{array}$ & $\begin{array}{l}80.7 \\
(46 / 57)\end{array}$ & $\begin{array}{l}57.9 \\
(11 / 19)\end{array}$ & NS & $* *$ \\
\hline
\end{tabular}

\footnotetext{
${ }^{1}$ Model-based means, from the appropriate analyses described in the statistical methods, for percentage of oocytes transvaginally aspirated on d 16 of the synchronized estrous cycle that had group II caspase activity, TUNEL labeling in the pronucleus, and that completed nuclear maturation to metaphase II after maturation in vivo. $\mathrm{NS}=$ not significant.$$
* P<0.05, * * P<0.01 \text {. }
$$ 


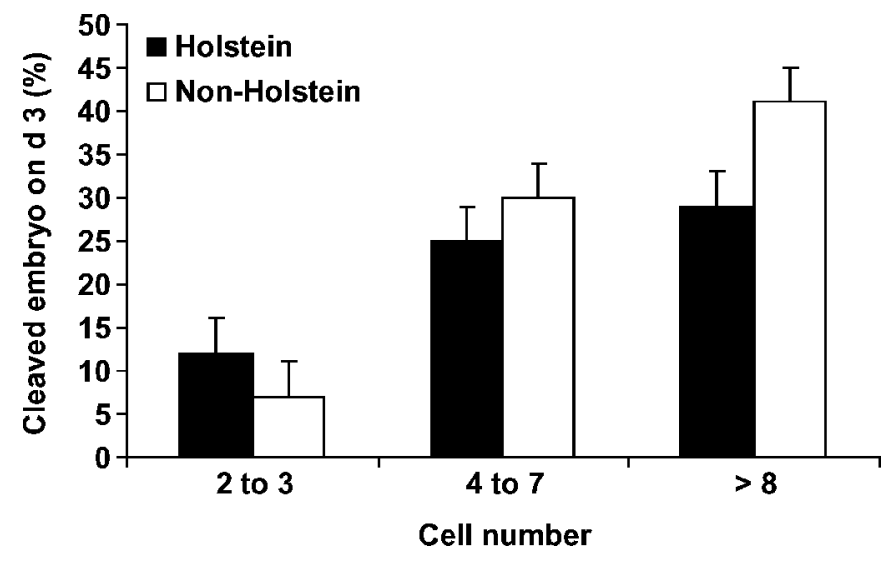

Figure 2. Percentage of cleaved embryos at either the 2- to 3-, 4to 7-, or >8-cell stage on $d 3$ following insemination of either Holstein $(n=115)$ or non-Holstein $(n=112)$ oocytes collected from slaughterhouse ovaries with semen from Angus bulls. The percentage of $>8$ cell stage embryos were reduced (breed by stage interaction, $P<0.10$ ) for embryos from Holstein oocytes compared with embryos from nonHolstein oocytes.

$(3.7 \pm 0.5 \mathrm{ng} / \mathrm{mL})$. The largest follicle on $\mathrm{d} 7$ was reduced $(P<0.05)$ in cows fed a diet enriched in $18: 1 c$ compared with all other diets (Table 5). Mean plasma concentrations of insulin and GH did not differ between treatment groups during the experimental sampling sequence. Mean plasma concentration of IGF-I tended to be lower $(P=0.06)$ for the group fed an 18:1c-enriched diet compared with the others (Table 6).

Utilizing the array of simple means for each cow, we examined correlations between IGF-I, GH, insulin, energy balance at the postpartum nadir, BCS at calving

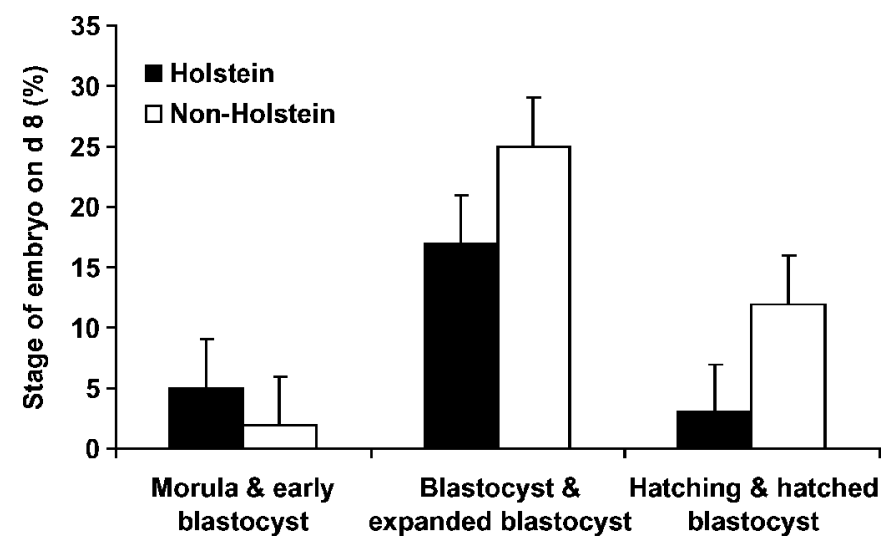

Figure 3. Percentage of embryos on d 8 following insemination based on the stage of development as affected by oocyte genotype. Stages of development were as follows: morula, early blastocyst, blastocyst, expanded blastocyst, hatching blastocyst, or hatched blastocyst. Embryos were produced from either Holstein $(n=115)$ or nonHolstein $(n=112)$ oocytes collected from slaughterhouse ovaries. The stage of blastocyst development on d 8 was more advanced (breed by stage interaction, $P<0.05$ ) in embryos from non-Holstein embryos. and 56 DIM, BCS loss, number of oocytes recovered at aspiration, percentage of oocytes undergoing cleavage, and percentage development to the morula and blastocyst stages. Correlations detected as significant were the following: percentage of oocytes undergoing cleavage was correlated with percentage development to morula and blastocyst $(\mathrm{r}=0.42, P<0.02)$; energy balance at the nadir was correlated with the percentage development to morula and blastocysts $(\mathrm{r}=0.42, P<$ 0.03 ); and plasma GH concentration was correlated with percentage development to morula and blastocysts $(\mathrm{r}=0.41, P<0.04)$. Although BCS at calving was correlated with energy balance at the nadir $(\mathrm{r}=-0.46, P=$ $0.02)$, BCS responses were not associated with the hormonal and OPU responses listed above. Pregnancy rate did not differ on either d 28 or 45 following AI (Table 5).

\section{DISCUSSION}

In this study, the source of supplemental fat enriched in different omega fatty acids affected follicle and CL sizes in lactating dairy cows during the summer but did not alter oocyte quality as determined by the subsequent capacity to form a developing embryo after in vitro fertilization. In a study by Hochi et al. (1999), embryos cultured in $0.3 \%$ 18:2-BSA had a reduced development to the morula stage and further reduced development to the blastocyst stage compared with embryos cultured in $0.3 \%$ BSA. Possibly increasing the 18:2 in the diet would have increased the amount of 18:2 in the oocyte, subsequently decreasing embryo development in vitro. However, the decrease observed in the present study was not significant. Homa and Brown (1992) cultured bovine oocytes from slaughterhouse ovaries with 18:2 and noticed a reduction in spontaneous germinal vesicle breakdown compared with oocytes cultured without fatty acids. In addition, follicular fluid from small vs. large follicles was analyzed for fatty acid concentrations, and 18:2 was the only fatty acid reduced in large but not small follicles. It is only after the follicle has grown to the large preovulatory stage that the inhibitory influence on resumption of meiosis in oocytes is released, under the influence of LH.

The caspase activity and TUNEL-labeling assay were used to indicate whether diets differing in fatty acid concentration could modulate the apoptosis pathway. Monounsaturated fatty acids prevented the proapoptotic effect of 16:0 in rat and human $\beta$-cells (Eitel et al., 2002). In addition, PUFA (18:2 and 18:3) suppressed apoptosis in W256 carcinoma cells (Tang et al., 1997). It may be possible to affect the composition of membrane fatty acids by dietary manipulations to reduce ceramide-induced apoptosis and protect the oocytes from thermal stress. Homa and Brown (1992) found 
Table 5. Mean follicle, corpus luteum (CL), and pregnancy responses from lactating multiparous and primiparous cows fed diets enriched in either 18:1 cis $(\mathrm{n}=14), 18: 1$ trans $(\mathrm{n}=14), 18: 2(\mathrm{n}=13)$, or $18: 3(\mathrm{n}=13)$ and transvaginally aspirated ${ }^{1}$

\begin{tabular}{|c|c|c|c|c|c|c|c|c|}
\hline Response & \multicolumn{4}{|c|}{ Treatment (Trt) } & SE & \multicolumn{3}{|c|}{ Contrast } \\
\hline CL number & 1.7 & 1.6 & 1.8 & 1.9 & 0.3 & NS & NS & NS \\
\hline CL volume, $\mathrm{mm}^{3}$ & 6,033 & 5,495 & 7,323 & 8,208 & 644 & NS & $*$ & NS \\
\hline \multicolumn{9}{|l|}{ Pregnancy rate } \\
\hline $\mathrm{d} 28$ & 28.6 & 30.8 & 16.7 & 23.1 & - & NS & NS & NS \\
\hline d 45 & 28.6 & 23.1 & 16.7 & 23.1 & - & NS & NS & NS \\
\hline
\end{tabular}

${ }^{1}$ Model-based means, from the appropriate analyses described in the statistical methods, for the largest follicle (mm) on $\mathrm{d} 0$ and 7 , CL number and volume $\left(\mathrm{mm}^{3}\right)$ on $\mathrm{d} 7$, plasma progesterone concentration $(\mathrm{ng} / \mathrm{mL})$ on $\mathrm{d} 7$, and pregnancy rate on d 28 and 45 following timed $\mathrm{AI}(\mathrm{d} 0) . \mathrm{NS}=$ not significant.

$* P<0.05$.

that 18:2 inhibited germinal vesicle breakdown and progression to metaphase II compared with unsupplemented oocytes (35 vs. $81 \%$ ), illustrating that $18: 2$ can affect nuclear maturation. However, in the present study, diet did not affect nuclear maturation as measured by caspase activity, TUNEL labeling, and progression to metaphase II.

Holstein and non-Holstein oocytes from slaughterhouse ovaries were used as an internal IVF control relative to OPU-collected oocytes from lactating Holsteins. Development to the blastocyst stage from Holstein vs. non-Holstein slaughterhouse oocytes was reduced on d 8 (21.2 vs. $35.1 \%)$. In addition, the average blastocyst development from all diets of OPU-collected oocytes $(5.6 \%)$ was lower than the Holstein slaughterhouse oocytes on $d$ 8. Reduction of blastocyst development in OPU oocytes appears not only to be due to the effect of breed, but may also be due to many other factors. Lactation may play a large part in the reduction of embryo development in OPU-collected lactating dairy cow oocytes compared with slaughterhouse oocytes, which were most likely from nonlactating cows. Gwazdauskas et al. (2000) collected oocytes throughout lacta-

Table 6. Means for plasma concentrations of growth hormone, IGF$\mathrm{I}$, and insulin of lactating dairy cows fed diets enriched in either 18:1 cis $(\mathrm{n}=14), 18: 1$ trans $(\mathrm{n}=14), 18: 2(\mathrm{n}=13)$, or $18: 3(\mathrm{n}=13)^{1}$

\begin{tabular}{lccccl}
\hline Plasma hormone, & & & & & \\
ng/mL & $18: 1 c$ & $18: 1 t$ & $18: 2$ & $18: 3$ & SEM \\
\hline Insulin & 0.64 & 0.61 & 0.64 & 0.58 & 0.04 \\
IGF-I $^{2}$ & 144.0 & 159.6 & 158.1 & 171.8 & 9.1 \\
Growth hormone & 7.4 & 7.5 & 7.9 & 5.6 & 1.1 \\
\hline
\end{tabular}

\footnotetext{
${ }^{1}$ Means represent model-based means and pooled SE from the appropriate analyses described in the statistical methods.

${ }^{2} 18: 1 c$ vs. rest, $P=0.06$.
}

tion by twice weekly OPU and concluded that the stage of lactation and dietary energy influenced the quality of oocytes. They also reported reduced oocyte quality and embryo development in lactating vs. nonlactating cows. Recently, Sartori et al. (2002) showed that embryos flushed from lactating cows were of lower quality than those from nonlactating cows. Another possibility is that slaughterhouse oocytes underwent a 4-h period before their removal from follicles and placement into maturation media, whereas OPU oocytes were placed into maturation media within 30 min following removal from the follicle. Blondin et al. (1997) collected slaughterhouse ovaries and held them in warm saline for different times postslaughter. The immature oocytes were then collected and IVF was performed. The maximum number of blastocysts obtained was after $4 \mathrm{~h}$ of incubation in warm saline (30\%) compared with half that at 2 $\mathrm{h}(15 \%)$. Oocytes collected from slaughterhouse ovaries underwent a postmortem effect in which the COC became less tightly connected to the follicle wall, and were therefore collected with a more complete morphology. The postmortem effect induces prematuration events that have beneficial effects on oocytes collected from slaughterhouse ovaries because embryo development was increased in vitro.

Zeron et al. (2001) showed that oocyte membrane fluidity is affected by temperature alterations between seasons, as well as by changes in fatty acid composition. Furthermore, a relationship was documented between decreased PUFA content, a change in the biophysical behavior of oocytes, and low fertility of dairy cows during summer. The number of high-quality oocytes was greater in ewes fed fish oil than in control ewes (74.3 and $57.0 \%$, respectively), and fish oil supplementation increased the proportion of long-chain unsaturated 
fatty acids in the plasma and cumulus cells (Zeron et al., 2002). However, these changes in fatty acid composition were relatively small in oocytes, indicating that uptake of PUFA to the oocyte is either selective or highly regulated.

A major difference between the study in ewes and the present study is that lactating dairy cows have a high utilization of fatty acids for lactation. An additional point in the present study was that dietary differences reflected different degrees of desaturation and isomerization of 18 fatty acids and there was no treatment group without supplementation of fatty acids. Perhaps oocyte quality may have been reduced from those harvested from cows not supplemented with fatty acids in comparison with cows supplemented with fatty acids. This study was conducted during the summer heat stress season and is a season in which Zeron et al. (2001) showed that MUFA and PUFA contents are lower in oocytes and granulosa cells compared with the winter season in dairy cattle. In the lactating cows used in the present study, there may have been a preferential uptake and utilization of fatty acids by tissues such as the mammary gland that did not permit a change or that sustained the reduced follicular contents of MUFA and PUFA. Consequently, the MUFA- or PUFA-enriched diets did not have profound effects on oocyte quality in vivo as measured by subsequent embryo quality in vitro.

The unsaturated fatty acids may have had a more profound effect on the environment surrounding the oocyte, which provides essential nutrients for oocyte or embryo survival postovulation. During the periovulatory period, oocytes go through nuclear and cytoplasmic maturation and fatty acids are acquired for cell structure, function, and metabolism. Storage of fatty acids, proteins, and mRNA are critical to early embryo survival before activation of its own genome. In this study, diets enriched in PUFA resulted in a larger follicle at AI (Table 5). A majority of the oocyte maturation occurs during its time in the dominant follicle. The present experimental approach of targeting oocytes from smaller follicles may not reflect the environment and control systems of the dominant periovulatory follicle. In smaller follicles, the fatty acids may not have been in sufficient amounts to have a beneficial effect on the oocyte, cumulus cells, or follicular fluid. For example, oocytes were aspirated from 3 - to 12 -mm follicles, which would not be preovulatory follicles in a lactating dairy cow (Sartori et al., 2002).

Others reported that supplemental fat increased the average size of the dominant follicle in lactating dairy cows (Beam and Butler, 1997). Dominant follicle size was increased in cows fed diets enriched in PUFA compared with cows fed a diet enriched in MUFA (Table
5), indicating that PUFA were the most effective (Staples et al., 2000). Diets enriched in different fatty acids appear to have differential effects on follicle development.

Larger ovulating dominant follicles in heifers, nonlactating dairy cows, and lactating dairy cows resulted in larger CL (Sartori et al., 2002). The CL volume was increased in cows fed PUFA-enriched diets compared with cows fed MUFA-enriched diets (Table 5). Lactating dairy cows fed an enriched diet of 18:2 had CL that were $5 \mathrm{~mm}$ larger than cows not fed fat (Garcia-Bojalil et al., 1998). Larger CL were detected with lactating dairy cows that received high amounts of $n-3$ fatty acids through the diet as formaldehyde-treated linseed or as a mixture of formaldehyde-treated linseed and fish oil (Petit and Twagiramungu, 2002). Larger CL may not only be due to ovulation of a larger follicle, but also to direct effects on the CL. Electron microscopic examination of the CL tissue revealed that the lipid content was greater in luteal cells from beef heifers fed $\mathrm{Ca}$ salts of palm oil compared with unsupplemented controls (Hawkins et al., 1995).

Although there were larger CL volumes in PUFAfed cows during the aspiration cycle (d 3 to 16 of the synchronized estrous cycle), progesterone concentrations did not differ among diets and did not differ on d 7 after AI. Previous studies have reported an increase (Staples et al., 1998), no effect (Bilby et al., 2006c), or a decrease (Robinson et al., 2002) in plasma progesterone in dairy cows supplemented with long-chain fatty acids.

Another biological window in which fatty acids may have had a beneficial effect is on the follicular, oviductal, or uterine environments. Cerri et al. (2004) fed lactating dairy cows a diet enriched in a mixture of 18:2 and 18:1t fatty acids and found an increase in fertilization rate, accessory sperm per structure, amount of high-quality embryos, and cell number when cows were flushed on d 5 following timed AI. In their model, oocyte maturation, fertilization, and embryo development occurred in vivo. Unsaturated fatty acids were shown to have beneficial effects on the uterine environment. Bilby et al. (2006a) reported that feeding lactating dairy cows Ca salts enriched in fish oil altered the gene expression in the endometrium of cyclic cows in a manner that mimicked the gene expression of pregnant cows. Also, the fish oil changed the fatty acid composition of the endometrium (i.e., increased eicosapentaenoic and docosahexaenoic acid and reduced arachidonic acid; Bilby et al., 2006b) in a manner that would reduce secretion of $\mathrm{PGF}_{2 \alpha}$ as reported in lactating dairy cows. By modulating prostaglandin production through fat feeding, it may be possible to change the follicular, 
oviductal, and uterine environments in a manner that alters both oocyte and embryo development.

Stage of the estrous cycle affected oocyte responses, with the first 2 aspirations (i.e., d 3 and 6 of the estrous cycle) generally being better than the last 2 aspirations (i.e., d 9 and 12). When dairy cow follicles were aspirated on $\mathrm{d} 2,5$, or 8 of an induced follicular wave, the proportion of oocytes competent to develop a blastocyst was greater on $\mathrm{d} 2$ and 5 compared with d 8 (Hendriksen et al., 2004). Lower rates of blastocyst development were reported when OPU was performed once a week in comparison with OPU every 3 to $4 \mathrm{~d}$ (Goodhand et al., 1999). Presumably, the higher frequency of OPU prevents the establishment of a dominant follicle. A dominant follicle clearly reduces the competence of oocytes from subordinate follicles. However, this impairment occurs rather late during the nongrowing phase of the dominant follicle (Hendriksen et al., 2004). In addition, Hendriksen et al. (2000) reported that follicles in the beginning of atresia had more competent oocytes that developed into blastocysts compared with oocytes from follicles that were not beginning atresia. Also, when an LH surge is induced prior to oocyte collection, prematurational events occur in the oocyte and further maturation of the follicle, allowing for an increased oocyte competence and subsequent embryo development (Hendriksen et al., 2000). In our study, cows were synchronized before OPU with an Ovsynch protocol plus a CIDR insert. Aspirations began 3 to $4 \mathrm{~d}$ following the last $\mathrm{GnRH}$ injection that ovulated the dominant follicle, leaving the slightly atretic subordinate follicles with oocytes undergoing prematurational events, possibly owing to better oocyte quality, recovery, and cleavage rate on the first OPU session compared with the other 4 sessions. Using OPU sessions of 3- and 4-d intervals, Bols et al. (1998) showed a decline from 9.6 oocytes per first OPU session to 3.9 in the second and an average of 6.2 oocytes from the fourth session onward. Also, Petyim et al. (2003) found that the presence of CLproducing progesterone had no influence on oocyte yields and quality, whereas the presence of dominant follicles appeared to decrease the number of recovered oocytes.

\section{CONCLUSIONS}

Feeding PUFA as compared with MUFA failed to affect oocyte quality, as demonstrated by subsequent embryo development. This suggests that the previously documented benefits of PUFA reflect actions at alternative biological windows. In this study, only small follicles (3 to $12 \mathrm{~mm}$ ) were aspirated so effects on periovulatory follicles would not be observed. Possible beneficial effects of PUFA on the periovulatory follicle and CL were evident by the increase in dominant follicle size and CL volume because of the feeding of PUFA (i.e., 18:2 and 18:3). Also, local effects of the fatty acid environment during nuclear and cytoplasmic maturation were eliminated because maturation occurred in vitro. Fatty acid composition of the diet could also alter the oviductal or uterine environment (i.e., gene expression) to promote embryo development. Further research is warranted in isolating particular fatty acids that may have beneficial effects on various biological windows that may alter fertility in lactating dairy cows.

\section{ACKNOWLEDGMENTS}

The authors thank the staff of the University of Florida Dairy Research Unit for assistance in feeding and managing the experimental cows. The authors also thank Select Sires for the donation of the semen and Intervet Inc. for the donation of Fertagyl. This journal article was supported by the Florida Agricultural Experiment Station. The study was partially funded by Church and Dwight, Inc. (Princeton, NJ), by NutriScience Technologies (Fairlawn, OH), and by Grant No. 2001-52101-11318 from the USDA Initiative for Future Agricultural and Food Systems.

\section{REFERENCES}

Beam, S. W., and W. R. Butler. 1997. Energy balance and ovarian follicle development prior to the first ovulation postpartum in dairy cows receiving three levels of dietary fat. Biol. Reprod. 56:133-142.

Bilby, T. R., A. Guzeloglu, L. A. MacLaren, C. R. Staples, and W. W. Thatcher. 2006a. Pregnancy, bovine somatotropin, and dietary n-3 fatty acids in lactating dairy cows: II. Gene expression related to maintenance of pregnancy. J. Dairy Sci. 89:3375-3385.

Bilby, T. R., T. Jenkins, C. R. Staples, and W. W. Thatcher. 2006b. Pregnancy, bovine somatotropin, and dietary n-3 fatty acids in lactating dairy cows: III. Fatty acid distribution. J. Dairy Sci. 89:3386-3399.

Bilby, T. R., A. Sozzi, M. M. Lopez, F. Silvestre, A. D. Ealy, C. R. Staples, and W. W. Thatcher. 2006c. Pregnancy, bovine somatotropin, and dietary n-3 fatty acids in lactating dairy cows: I. Ovarian, conceptus and growth hormone-insulin-like growth factor system response. J. Dairy Sci. 89:3360-3374.

Blondin, P., K. Coenen, L. A. Guilbault, and M. A. Sirard. 1997. In vitro production of bovine embryos: Developmental competence is acquired before maturation. Theriogenology 47:1061-1075.

Bols, P. E. J., M. T. Ysebaert, A. Lein, M. Coryn, A. Van Soom, and A. de Kruif. 1998. Effects of long-term treatment with bovine somatotropin on follicular dynamics and subsequent oocyte and blastocysts yield in an OPU-IVF program. Theriogenology 49:983-995.

Cerri, R. L. A., R. G. S. Bruno, R. C. Chebel, K. N. Galvao, H. Rutgliano, S. O. Juchem, W. W. Thatcher, D. Luchini, and J. E. P. Santos. 2004. Effect of fat sources differing in fatty acid profile on fertilization rate and embryo quality in lactating dairy cows. J. Dairy Sci. 87(Suppl. 1):297. (Abstr.)

Eitel, K., H. Staiger, M. D. Brendel, D. Brandhorst, R. G. Bretzel, H. Häring, and M. Kellerer. 2002. Different role of saturated and unsaturated fatty acids in $\beta$-cell apoptosis. Biochem. Biophys. Res. Commun. 299:853-856.

Fouladi-Nashta, A. A., C. G. Gutierrez, H. F. Russell, P. C. Garnsworthy, and R. Webb. 2004. Effects of dietary fatty acids on oocyte 
quality and development in lactating dairy cows. Biol. Reprod. Special Issue: 107. (Abstr.)

Garcia-Bojalil, C. M., C. R. Staples, C. A. Risco, J. D. Savio, and W. W. Thatcher. 1998. Protein degradability and calcium salts of long-chain fatty acids in the diets of lactating dairy cows: Reproductive responses. J. Dairy Sci. 81:1385-1395.

Goodhand, K. L., R. G. Watt, M. E. Staines, J. S. M. Hutchinson, and P. J. Broadbent. 1999. In vivo oocyte recovery and in vitro embryo production from bovine donors aspirated at different frequencies or following FSH treatment. Theriogenology 51:951961.

Gwazdauskas, F. C., K. W. Kendrick, A. W. Pryor, and T. L. Bailey. 2000. Impact of follicular aspiration on folliculogenesis as influenced by dietary energy and stage of lactation. J. Dairy Sci. 83:1625-1634.

Hawkins, D. E., K. D. Niswender, G. M. Oss, C. L. Moeller, K. G. Odde, H. R. Sawyer, and G. D. Niswender. 1995. An increase in serum lipids increases luteal lipid content and alters the disappearance rate of progesterone in cows. J. Anim. Sci. 73:541-545.

Hendriksen, P. J. M., W. N. M. Steenweg, J. C. Harkema, J. S. Merton, M. M. Bevers, P. L. A. M. Vos, and S. J. Dieleman. 2004. Effect of different stages of the follicular wave on in vitro developmental competence of bovine oocytes. Theriogenology 61:909-920.

Hendriksen, P. J. M., P. L. A. M. Vos, W. N. M. Steenweg, M. M. Bevers, and S. J. Dieleman. 2000. Bovine follicular development and its effect on the in vitro competence of oocytes. Theriogenology $53: 11-20$.

Hochi, S., K. Kimura, and A. Hanada. 1999. Effect of linoleic acidalbumin in the culture medium on freezing sensitivity of in vitroproduced bovine morulae. Theriogenology 52:497-504.

Homa, S. T., and C. A. Brown. 1992. Changes in linoleic acid during follicular development and inhibition of spontaneous breakdown of germinal vesicles in cumulus-free bovine oocytes. J. Reprod. Fertil. 94:153-160.

Jousan, F. D., and P. J. Hansen. 2004. Insulin-like growth factor-I as a survival factor for the bovine preimplantation embryo exposed to heat shock. Biol. Reprod. J. Dairy Sci. 71:1665-1670.

Kramer, J. K. G., V. Fellner, M. E. R. Dugan, F. D. Sauer, M. M Mossoba, and M. P. Yurawecz. 1997. Evaluating acid and base catalysts in the methylation of milk and rumen fatty acids with special emphasis on conjugated dienes and total trans fatty acids. Lipids 32:1219-1228.

NRC. 2001. Nutrient Requirements of Dairy Cattle. 7th rev. ed. Natl. Acad. Press, Washington, DC.
Parrish, J. J., J. L. Susko-Parrish, M. I. Liebfried-Rutledge, E. S. Critser, W. H. Eyestone, and N. L. First. 1986. Bovine in vitro fertilization with frozen-thawed semen. Theriogenology 25:591-600

Petit, H. V., and H. Twagiramungu. 2002. Milk production and composition, ovarian function, and prostaglandin secretion of dairy cows fed omega-3 fats. J. Dairy Sci. 85:889-899.

Petyim, S., R. Bage, T. Hallap, A. S. Bergqvist, H. Rodriguez-Martinez, and B. Larsson. 2003. Two different schemes of twice-weekly ovum pick-up in dairy heifers: Effect on oocyte recovery and ovarian function. Theriogenology 60:175-188.

Robinson, R. S., P. G. A. Pushpakumara, Z. Cheng, A. R. Peters, D. E. E. Abayasekara, and D. C. Wathes. 2002. Effects of dietary polyunsaturated fatty acids on ovarian and uterine function in lactating dairy cows. Reproduction 124:119-131.

Sartori, R., G. J. M. Rosa, and M. C. Wiltbank. 2002. Ovarian structures and circulating steroids in heifers and lactating cows in summer and lactating and dry cows in winter. J. Dairy Sci. 85:2813-2822

Soto, P., R. P. Natzke, and P. J. Hansen. 2003. Identification of possible mediators of embryonic mortality caused by mastitis: Actions of lipopolysaccharide, prostaglandin $\mathrm{F}_{2 \alpha}$, and the nitric oxide generator, sodium nitroprusside dehydrate, on oocyte maturation and embryonic development in cattle. Am. J. Reprod. Immunol. 50:263-272.

Staples, C. R., J. M. Burke, and W. W. Thatcher. 1998. Influence of supplemental fats on reproductive tissues and performance of lactating cows. J. Dairy Sci. 81:856-871.

Staples, C. R., M. C. Wiltbank, R. R. Grummer, J. Guenther, R. Sartori, F. J. Diaz, S. Bertics, R. Mattos, and W. W. Thatcher. 2000. Effect of long-chain fatty acids on lactation performance and reproductive tissues of Holstein cows. J. Dairy Sci. 83(Suppl. 1):278. (Abstr.)

Tang, D. G., K. L. Guan, L. Li, V. H. Kenneth, Y. Q. Chen, and R. L. Rice. 1997. Suppression of w256 carcinosarcoma cell apoptosis by arachidonic acid and other polyunsatured fatty acids. Int. J. Cancer 72:1078-1087.

Zeron, Y., A. Ocheretny, O. Kedar, A. Borochov, D. Sklan, and A. Arav. 2001. Seasonal changes in bovine fertility: Relation to developmental competence of oocytes, membrane properties and fatty acid composition of follicles. Reproduction 121:447-454.

Zeron, Y., D. Sklan, and A. Arav. 2002. Effect of polyunsaturated fatty acid supplementation on biophysical parameters and chilling sensitivity of ewe oocytes. Mol. Reprod. Dev. 61:271-278. 